\title{
Resisting the hospice narrative in pursuit of quality of life
}

\author{
Jillian A. Tullis, ${ }^{1}$ Lori A. Roscoe, ${ }^{2}$ Patrick J. Dillon ${ }^{3}$
}

${ }^{1}$ Department of Communication Studies, University of San Diego, San Diego, CA; ${ }^{2}$ Department of Communication, University of South Florida, Tampa, FL; ${ }^{3}$ School of Communication Studies, Kent State University at Stark, North Canton, OH, USA

\begin{abstract}
The overall hospice philosophy is to provide care that enhances a dying person's quality of life. Most individual's quality of life is improved when they embrace hospice eligibility and reimbursement requirements, such as stopping burdensome and ineffective curative treatment, addressing pain and other symptoms, and seeking avenues for closure. However, this institutionalized prescription for enhancing quality of life at the end of life does not work for all patients. This article considers what happens when patients' personal definitions of quality of life at the end of life resist the prevailing narrative of appropriate hospice care. Using a series of examples from more than 600 hours of participant observation, our findings reveal narratives of resistance that fall into three themes: i) patients and/or family members who deny the imminence of death despite an admission to hospice; ii) patients who request treatments usually defined as curative; and iii) patients who resist the organizational constraints imposed by the institutionalization of the hospice model of care. Analysis of these themes illustrates the subjective nature of quality of life at the end of life and the pressures of standardization that may accompany the growth and maturity of the hospice industry in the United States.
\end{abstract}

\section{Introduction}

Hospice, first envisioned by Dame Cicely Saunders, is a philosophy of care focused on helping dying people

Correspondence: Jillian A. Tullis, Department of Communication Studies, University of San Diego, 5998 Alcalá Park, San Diego, CA 92110, USA.

Tel: +1.619.260.6897 - Fax: +1.619.260.4205

Email: jtullis@sandiego.edu

Acknowledgements: We would like to express our sincere thanks to the hospice patients and families who allowed us into their lives during this sacred time. And to the dedicated hospice staff for their time and commitment to the people they serve.

Key words: Death; End of life; Medical communication; Palliative care.

Contributions: each author collected data independently for this study and each contributed to the drafting and editing of the manuscript. Each author will be responsible for final approval of the final version of the essay should it be published.

Conflict of interest: the authors declare no potential conflict of interest.

Note: portions of this manuscript were presented at the National Communication Association conference in Las Vegas, Nevada in November 2015.

Received for publication: 11 July 2016

Revision received: 10 March 2017.

Accepted for publication: 14 March 2017.

This work is licensed under a Creative Commons Attribution NonCommercial 4.0 License (CC BY-NC 4.0).

CCopyright J.A. Tullis et al., 2017

Licensee PAGEPress, Italy

Qualitative Research in Medicine \& Healthcare 2017; 1:63-72

doi:10.4081/qrmh.2017.6152 experience a good death, or a death free of physical and spiritual pain. ${ }^{1,2}$ Saunder's approach to caring for the dying included addressing what she called total pain that is, pain constituted by physical as we all as spiritual, emotional, or psychological suffering. ${ }^{2}$ Contemporary hospice organizations continue to draw on Saunder's inspiration and provide terminally ill patients and their families with whole person care, which addresses the five dimensions of quality of life (Figure 1). ${ }^{3}$ This type and level of care is accomplished by an interdisciplinary team, and each member of the team is responsible for addressing at least one of the quality of life dimensions. The goal of maximizing quality of life over quantity of life is accomplished in part through pain and symptom management (palliation) known as palliative care. A hospice patient must, therefore, be primarily interested in a palliative plan of care and willing to discontinue curative treatments. In 2014, however, the Centers for Medicare \& Medicaid Services announced the Medicare Care Choices Model - an experimental program that will allow Medicare beneficiaries to receive hospice-like support services from certain hospice providers while concurrently receiving services provided by their curative care providers. ${ }^{4}$ The model will be phased in and evaluated over a two-year period beginning in 2016. Aside from such experimental programs, forgoing curative treatment is a sign that the patient acknowledges her illness will likely end her life. The use of palliative care speaks to the philosophical commitment that undergirds hospice - to improve and maintain a dying person's quality of life until their last breath. Comfort is an essential characteristic of hospice care because adequate pain and symptom management alongside psychological and spiritual well-being enhances patients' quality of life, and re- 
search has consistently demonstrated its importance to dying patients and their families, , $^{25-10}$

While all hospices are driven by the same goal - a good death that is natural and pain free - the focus on quality of life is more complicated to achieve than managing or alleviating a patient's physical or psychic pain. Minimizing all sources of suffering is key, and so is maximizing sources of pleasure, joy and meaning in a dying person's life. Quality of life is subjective and multifaceted; therefore, it can be defined quite differently from person to person. ${ }^{11}$ The hospice philosophy espouses an individualized approach to care developed in conjunction with patients (and their loved ones) to address these variations, yet in practice there are limitations placed upon hospice organizations that can undermine individual patients' quality of life goals and the founding principles of hospice. For example, some medical treatments considered curative, which might contribute positively to a patient's quality of life, are prohibited because of reimbursement rules and costs. Most hospices in the United States are reimbursed for care through a national healthcare program known as Medicare. Hospices receive a daily per diem for hospice services. The price is fixed and not influenced by the extent of care provided. Chemotherapy is usually considered a curative treatment modality, but in some cases can be palliative; tumors may shrink and cause less discomfort, and some patients report a psychological boost from continuing chemotherapy. ${ }^{12}$ The bulk of hospice care is delivered during a typical eight hour business day, with very little care provided in the evenings, at nights, or on weekends, despite a patient's or their family caregiver's needs. Health care practitioners' training about what constitutes medically necessary care, symptom management, and criteria for admission and on-going certification in hospice can also sometimes work counter to patients' conceptions about what contributes to their comfort and quality of life. For example, giving patients enough pain medication to fully control their pain may also leave them drowsy and unable to interact with their family members.

As Bochner, Ellis, and Tillman-Healy explain, canonical narratives are those that represent the 'right story' which, on the whole, is taken for granted as the way things are supposed to work..$^{13,14}$ In conjunction with institutional policies and procedures (at the political and organizational level) that regulate access and formally define legitimate behaviors within the hospice system, the canonical narrative associated with hospice care influences what is possible for patients and their loved ones at the end of life. The prevailing hospice narrative about a good death might vary slightly from state to state and from agency to agency, but generally conforms to the following values. A natural, pain-free death is the goal; therefore, any actions that would hasten or prolong the dying process are discouraged and prohibited. Quality of life is preferable to quantity of life. Patients should seek comfort care rather than treatments designed to cure disease or prolong life (keeping in mind that good pain and symptom management often do result in patients living longer). ${ }^{15,16}$ Most patients wish to die at home, and most hospice care is pro-

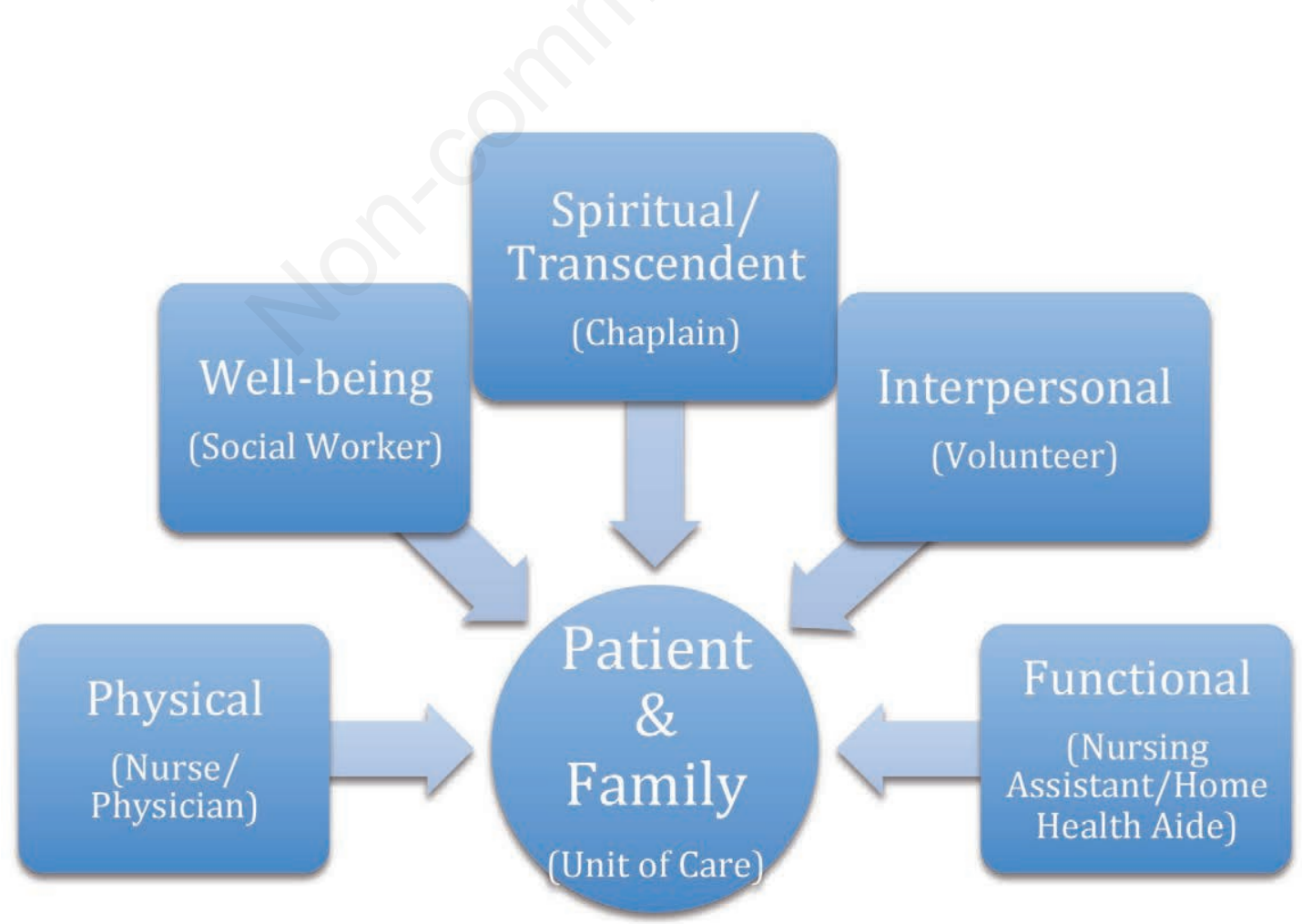

Figure 1. Five quality of life dimensions that guide hospice care. 
vided in residential settings, which include nursing homes and assisted living facilities. ${ }^{17}$ The unit of care is the patient and family (as designated by the patient), not the patient-physician dyad, and family caregivers' concerns and needs must also be taken into account. The hospice philosophy and the practices that constitute hospice care combine to create a narrative that includes acceptance of death as a natural part of life that should not be prolonged nor accelerated, where pain and suffering are controlled, and where hospice staff hold the expertise to help patients accomplish a good death. A common refrain in hospice is that practitioners take their knowledge of palliative care and come alongside hospice patients and their families, and meet them where they are to work together on their journey towards a good death..$^{18-20}$

Many writers and scholars ${ }^{17-20}$ have argued that dying and death are experiences many people are sheltered from due to medical advances, industrialization, and cultural and social norms. Patients and their loved ones are at a disadvantage when faced with a terminal illness, as a hospice admission may be the first time anyone has ever wanted to talk about what a good death may mean or how it might be accomplished. Therefore, an organization such as hospice that openly accepts death as a natural part of life can offer several benefits. For patients and their loved ones, the foundations of hospice mean an interdisciplinary team will offer support in the form of their expert knowledge about the dying experience that addresses physical pain as well as existential suffering. More specifically, hospice staff will engage in conversations that allow them to assess the medical, social, psychological, and spiritual needs of patients and their families. For example, if there are conflicts among siblings about what type of care their mother wants or needs, hospice staff possess the skills to not only recognize these issues, but also address them. Should a patient have limited social connections, miss attending church, or have limited mobility that makes bathing difficult, hospice will respond with visits from a volunteer, a chaplain, or home health aide, respectively. Hospice should not only help educate patients and their family caregivers about the dying process, but also respond as patients decline and their needs and desires change. Patients and families should find the types of questions that guide hospice care different from other types of healthcare because in order for a patient to live fully until she dies, and to address her needs during the dying process, communication about what makes life meaningful is necessary, as well as what is happening with the patient emotionally and physically. Patients and families will not be abandoned in their time of need when curative medicine is no longer an option, but instead will be cared for until the end.

Hospice has evolved significantly since Saunders founded St. Christopher's in London and its subsequent migration to the United States in the 1970s. Once an allvolunteer social movement actively resisting the medical- ization of dying and death, and paternalistic approaches to care at the end of life that dehumanized individuals, it is now a highly structured medical institution that has come to define the right way to die. ${ }^{21}$ These processes and structures influence the ways in which hospice staff and patients communicate and work together to accomplish a good death. ${ }^{22}$ While there is a clear narrative within hospice, it is less clear what happens when patients' experiences and goals do not fall neatly into the existing dominant hospice narrative. In this manuscript we explore three themes to understand how patients and families enact resistance in hospice settings. We discuss the instances in which a dying patient's ideas about quality of life ran counter to the hospice narrative about what constitutes a good death. We present and analyze patients' opposition to plans of care and how they communicated their quality of life needs. And finally, we consider how the ways in which these messages are understood and acted upon by hospice staff members provides a unique examination of both patient and practitioner communication. The concept of narratives of resistance provides a useful theoretical framework to understand the significance of these interactions and their outcomes.

\section{Narratives of resistance}

Human beings are not condemned to live out particular stories, even powerful canonical narratives, without hope for change. ${ }^{13,14}$ Part of the power of narrative is the ability to account for how one's actions deviate from alternative narratives in ways that make them seem reasonable or justified..$^{14}$ As Bochner and colleagues note, social actors continually (re)create the social world through introducing new stories and altering existing narratives within particular cultural and structural systems. ${ }^{13}$ Mishler calls patients' stories that fall outside the boundaries of our expectations in healthcare contexts narratives of resistance. $^{23}$ These counter narratives, or what Stone-Mediatore calls marginal experience narratives, are representations that allow alternate perspectives that may be missing or underrepresented to be communicated and acted-upon. ${ }^{24}$ Narratives of resistance are important to identify and attend to because they help us examine taken-for-granted assumptions, can change cultural scripts, and present different ways of experiencing and communicating about health..$^{24}$ According to Stone-Mediatore, narratives from dominant perspectives tend to be endorsed and repeated by powerful institutions, with the result that the narrative character of these representations passes unnoticed as they come to be accepted as 'common sense' 'knowledge. ${ }^{24}$ Stories of patients who refuse to follow their physicians' recommended course of treatment in order to meet some other goal run counter to the cultural and social assumption that doctors know best. For example, a patient may tell her physician that she will not take the prescribed pain medication so that she can stay coherent enough to communicate with visitors. It may seem like common sense to 
control pain, especially in hospice, and as such, the decision to focus on pain control is a priority or value held by the institution and its members that is rarely questioned.

Narratives of resistance provide alternative forms of knowledge important for countering dominant narratives and incorporating already marginalized individuals into society. ${ }^{13,14,24}$ According to Mishler, physicians and other healthcare practitioners focus on the Voice of Medicine (which centers on talk about symptoms and treatment options) and not the Voice of the Lifeworld (where patients' discourse and concerns concentrate on the everyday effects of illness).$^{23}$ As a result, patients' concerns about how their illness might affect their lives and overall wellbeing might be ignored, even by hospice organizations with an explicit mission to attend to patient-specific preferences and values. Narratives of resistance, if they are attended to by practitioners, can help patients feel as if they have some control and a voice in the process of their care. Further, such stories about resistance can reveal issues of power and hierarchy within the patient-physician relationship, or between the hospice philosophy and reimbursement structures and patient preferences. As Dutta notes, attending to such narratives of resistance is a necessary first step toward transforming restrictive (or oppressive) institutional policies and practices. ${ }^{25}$ We next describe the approach used to identify and analyze such narratives of resistance in hospice, and then discuss the themes that emerged from our analysis.

\section{Methods}

This investigation of narratives of resistance draws upon existing data from approximately 600 hours of participant observation and interviews with hospice patients and lay caregivers at three not-for-profit hospices in the Southeastern United States. These earlier ethnographic projects all received Institutional Review Board approval at the authors' respective institutions and study sites. Other findings from these data have been published elsewhere. ${ }^{22,26-29}$ In each of these studies, our methods included audiotaped and transcribed interviews, and detailed field notes of our observations. What we noticed in the course of pursuing these studies was that some patient narratives about their experiences with hospice care fell outside of the goals of those projects. In each of these other studies, although not common, some narratives of resistance were present and deserving of exploration in their own right. A re-examination of our field notes and interview transcriptions revealed instances in which conflict related to a patient's hospice plan of care arose. These cases were further analyzed and three themes, threads which run through the data, were identified. ${ }^{30}$

The examples discussed here are based upon actual patient interactions, therefore, pseudonyms are used to protect the confidentiality of patients and their families. In some cases diagnoses and other personal details have been changed to further safeguard patients and the hospice staff who provided care. The exemplars presented sort into three themes: i) patients and/or family members who deny the imminence of death even though they have been admitted to hospice care; ii) patients who request treatments usually defined as curative which challenge the hospice philosophy of palliative care; and iii) patients who resist the organizational constraints imposed by the institutionalization and bureaucratization of hospice. These themes describe the ways in which patients resisted the dominant conceptions about what constitutes quality of life put forth by the prevailing hospice model of care.

\section{Denying the imminence of death}

Americans live in a death-denying culture and are socialized to believe that a prescription medication or procedure at a particular hospital or cancer center can all but render death optional. Doctors routinely over-estimate life expectancy after serious illnesses are diagnosed, ${ }^{31}$ use euphemistic language to convey prognostic information, ${ }^{32}$ or avoid the subject of death altogether. ${ }^{33}$ Patients admitted to hospice might still wish to deny they have a limited life expectancy. The first theme of resistance narratives highlights patients and family members who deny or resist the imminence of death, even though they have accepted admission to hospice care (which requires a limited life expectancy). For example, three hospice patients with cancer shared stories in their interviews that centered on their unmet expectations for physical improvement. Although these patients understood that hospice is end-oflife care, they agreed to receive hospice care believing that they would soon be well enough to return to curative treatment. Kevin, a 58-year-old patient with cancer, explained:

When I started hospice, I was thinking it would be like a time-out from my treatments. I had lost a bunch of weight and wasn't feeling great. I don't think it's the cancer though; I think it's the treatment. I don't think I'm dying from the cancer yet, but I couldn't go on with the treatment and the stuff that came with hospice things I wouldn't have otherwise - sounded good. So, I said I'd do it, but there's no doubt in my mind that I'll be back to chemotherapy as soon as I can.

Mandy, a 72-year-old patient with cancer, described a similar experience. I'm happy with the hospice people and everything, but I thought I wouldn't be doing this for so long. My neighbor's sister had been in hospice and got better. I was hoping it would be the same for me, she explained.

The belief that hospice care would serve as a break or as a way to prepare for additional treatment also extended to patients' family members. For example, Geraldine and Carla - two women who served as the primary caregivers for their mothers - both recounted viewing hospice as a mechanism for their mothers to regain their strength before resuming treatment. As Carla stated:

Yeah, hospice, the lady from hospice, I talked to them. She was saying stuff like it could be a couple of 
weeks, a couple of months, a couple of years, nobody knows, you know that sort of thing. So I was not thinking weeks, that part, I guess I didn't focus on, I didn't hear, I am not sure what happened with that. I was just thinking that, you know, she was gonna spend some time recovering and then she'd be back with the doctor. That was my hope. It was my only focus. Getting her better and back to being treated. It didn't happen. She only lived for three more weeks.

While Carla expressed disappointment that her mother died soon after entering hospice care, Geraldine noted that, at the time of our interview, her mother was doing better and was getting closer to going back to the doctor.

When people make sense of terminal illness and hospice care, it is often intertwined with conceptions of hope ${ }^{34}$ As patients and caregivers found themselves living in what Ellis described as two simultaneous realities —one in which the end of life was near and one where recovery was still possible - it was clear that many attempted to maintain the more hopeful frame that they or their loved one would eventually overcome their illness. ${ }^{34}$ When asked why they were in hospice, Bonnie responded for her husband Frank (62-years-old) saying, the doctor just thought we could use more help, never acknowledging that terminal mesothelioma was the diagnosis that warranted Frank's admission to hospice.

These stories demonstrate the complexities of hope in the context of terminal illness and hospice care, but they can also provide hospice staff charged with caring for patients with valuable information about families' orientation to care and to dying. In a persistently death avoidant society like the United States, where patients [and their loved ones] experience illness as a breach, an interruption, or a rupture in their life story, and doctors comprehend death largely as a defeat, a hopeful future often becomes synonymous with returning to a previously healthy state. ${ }^{35}$ While this frame may serve a valuable sensemaking function and aid in coping, it may also make it more difficult for hospice staff to help patients and families address the realities of impending death. Patients, for example, may delay getting their affairs in order, making funeral plans, or seeking closure in important relationships; hence, while it may appear entering hospice care means patients and their loved ones have started moving down a path of accepting that death is near, these narratives of resistance suggest this may not always be the case, calling into question the significance of acceptance to achieve a good death.

These stories also raise questions about the necessity of accepting the inevitability of one's death in order to enter hospice care. Approximately one in five (i.e., more than 280,000) hospice patients are discharged alive each year; many of these patients return to curative treatment. ${ }^{36}$ These data suggest that patients' and families' hopes for recovery and/or continued treatment are not wholly misguided, even if they remain the less likely outcomes. Pre- vious studies suggest, however, that patients and their families may be unwilling to share such hopes if they fear that they will be denied hospice services; ${ }^{37}$ furthermore, in some cases, maintaining hope for recovery (even while acknowledging that the end of life may be near) is tied to important cultural and religious beliefs/values. ${ }^{38}$ It may, thus, be more productive for hospice providers to encourage patients and families to express such hopes and work through them rather than overtly (or tacitly) discourage such disclosures.

\section{Requesting curative treatments}

Another category of resistance narratives focuses on patients who continue to request curative treatments following an admission to hospice. Some hospice organizations are able to offer these more intensive and expensive treatments; for instance, approximately half of the hospices in the U.S. permit admitted cancer patients to continue with chemotherapy while under hospice care. ${ }^{12}$ Schonwetter and colleagues compared hospice patients who continued chemotherapy with a control group of hospice patients who discontinued chemotherapy upon admission to hospice. ${ }^{12}$ Findings revealed that the patients in both groups were similar in reported symptom distress, but patients who continued receiving chemotherapy reported significantly more subjective benefit, although the groups showed no difference in survival rates. Some patients reported that continuing chemotherapy helped them remain hopeful about their prognosis, and they received a psychological benefit from continuing to fight their disease. For these patients, the symbolic meaning of continuing to fight their disease contributed positively to their quality of life.

In our observations, we have also met patients and families who are committed to physical therapy and maintaining exercise regimes, despite risk for falls or increased pain, in hopes of getting stronger and recovering. For some patients, unusual medical interventions or treatments contraindicated for patients with limited life expectancy are exactly what is desired and needed to promote quality of life.

Consider the request of Bill, a 76-year-old hospice patient with Stage IIIB non-small cell lung cancer, who subsequently developed bradycardia (slow heart beat). After a thorough evaluation, his cardiologist (who treated cancer patients exclusively), recommended a pacemaker. The patient was apprised of the benefits and burdens of this intervention, including the information that the pacemaker could be discontinued at any time at Bill's request, and provided informed consent. Within two days, the patient was discharged to his home, where the device relieved his shortness of breath and periodic fainting, and permitted him to walk unaided from his bed to his living room couch, which he reported was a great joy to him during his last month of life. Once Bill entered the active phase of dying, however, he requested deactivation of his pacemaker. 
While the insertion of the pacemaker contributed to Bill's quality of life, discontinuing pacemakers and other implantable cardiac devices at the end of life remains controversial..$^{39}$ Some ethicists make distinctions between devices that replace an organ or body part (such as a transplanted kidney), which become an organic part of the patient; these cannot ethically be removed, even when a patient is dying. ${ }^{40}$ Substitutive devices (such as implantable cardioverter-defibrillators or ICDs) also provide a lost function but do not become organic body parts and so can be discontinued at the patient's or surrogate's request. ${ }^{41}$ Pacemakers fall somewhere in between organic body part and substitutive device. Of a survey of over 5000 medical professionals, legal professionals and patients, most respondents thought device therapy should be withdrawn if the patient requested its withdrawal at the end of life. Opinions of medical professionals and patients, however, tended to be dependent on the type of device, with turning off ICDs being perceived as more acceptable than turning off pacemakers, whereas legal professionals tended to perceive all devices as similar. ${ }^{42}$ What is most important is that conversations about deactivation begin when patients and physicians are discussing whether or not to implant a device. ${ }^{43}$ This controversy cannot be avoided among patients who enter hospice care with implantable devices, so the question becomes whether the patient's enhanced quality of life, even for a short time, is worth the subsequent controversy or additional decision making about discontinuing pacemaker support.

Sonia, a 79-year-old hospice patient with widely metastatic breast cancer, described her primary joy in life as watching television. Unfortunately, Sonia had cataracts, which made this activity impossible. Cataract surgery is generally a low risk, outpatient procedure with almost guaranteed results. Sonia was only expected to live for a few weeks, so hospice staff questioned whether undergoing surgery was advisable, even if it would undoubtedly enhance her quality of life. Sonia thought so and her surgery was successful, even though her hospice care providers strongly cautioned her against undergoing surgery given her complex medical status and prognosis. Both Bill's and Sonia's stories raise philosophical issues and ethical dilemmas. Yet both were highly satisfied with the interventions they chose, which not only improved their quality of life, but also enhanced their autonomy, both of which are important to patients who are dying and foundational to achieving a good death..$^{5-10}$

Although the previous two cases had positive outcomes for the patients, it is important to acknowledge that not all requested interventions or narratives of resistance lead to favorable outcomes. Jane, a 58-year-old matriarch, was dying of breast cancer and eventually stopped eating. She showed no interest in food and was unable to feed herself, which is a natural aspect of the dying process. Jane's family insisted on tube feeding. This request met the family's emotional need to feed their loved one, and perhaps in their minds ensured her quality of life, it also contradicted the hospice narrative that patients should not request or accept futile treatment. In this case, the hospice staff relented, at least temporarily, and the results were devastating. Jane, unable to digest the nutrition, began vomiting feces.

In the case of Jane, it's not clear if tube feeding is what she would have wanted if she could have spoken for herself. What is more clear is that moments of resistance that run counter to the hospice philosophy can challenge hospice staff to communicatively manage the dialectical tension between replacing aggressive treatment with palliative care while at the same time valuing patients' and their loved ones' preferences and subjective definitions of quality of life. Jane's story reveals the consequences of relying too heavily on one dimension of quality of life with a missed opportunity to consider the well-being and spiritual dimensions of care to address the basis of this family's resistance. This example also demonstrates the deleterious effects of failing to engage in the type of dialogical communication necessary to best manage conflict and tension regarding a patient's plan of care.

\section{Refusing to accept organizational constraints}

The third theme we examine here are patients who refuse to accept organizational constraints as part of hospice care. Two cases, both involving women with terminal cancer, illustrate this theme. Mary, a 58-years-old, was dying of colon cancer but had also used a wheelchair for 30 years because of mobility issues caused by Parkinson's disease. As months passed, Mary's colon cancer worsened and she got weaker and more dependent upon help with activities of daily living. Since she lived at home and had no familial support nearby, Mary hired home health aides to supplement the care she was receiving from hospice during business hours. Determined to die at home - one of hospice's commitments to their patients - Mary increased the home health aide support as her physical abilities declined. The home health aide provided by hospice became a beloved caregiver until one day when she was suddenly and unexpectedly removed from Mary's care team with no explanation. The hospice home health aide's replacement was disrespectful and repeatedly made derogatory comments about Mary's body and bodily functions. The aide complained about how Mary smelled while changing her after a bowel movement and grimaced at the sight of the wound caused by the cancer in her breast.

Mary was beside herself about the change, and felt demeaned by the new staff member, but she refused to speak up. She has outlived her initial prognosis of six months, and she feared that a formal complaint would only lead to reprisal in the form of worse care or being discharged from hospice, the latter of which would force her into a nursing home. Mary felt tremendous anxiety about the possibility of being moved into a nursing home, but was humiliated by a member of her hospice team; the lack of 
control she had about who would care for her all compromised her quality of life. Mary's insistence that she die at home, but more importantly her silence regarding her care, was her resistance.

The second example of refusing organizational constraints involves, Angela, a 35-year-old mother of five diagnosed with breast cancer, complicated by morbid obesity and a fractured disc in her back. Angela and her children moved in with her sister and brother-in-law after her diagnosis. Bed-ridden and dependent on her brother-in-law for the majority of her care, Angela could only have visits from the volunteer, chaplain, or nursing staff when her brother-in-law or her sister approved. Angela's sister and brother-in-law were less than willing to let hospice dictate the schedule of care. While this was a source of frustration for the hospice team and for Angela as well, it was one way for this family to resist the hospice narrative that includes a passive and accommodating patient and family. As a result of these conflicts, several members of the hospice team were pulled from service and prohibited from visiting. The hospice team leader did not attempt any problem solving - the family was told they would have to conform or lose care - and there was no conversation during team meetings about why Angela's family caregivers were reticent to freely accept hospice services on the organization's terms. For almost two weeks, Angela received no social or spiritual support before she died.

Both of these exemplars have one thing in common, hospice teams neglected to inquire about why their patients and families were resisting. They did not attempt to empower patients, and instead opted to assert organizational control, one that maintains hospice staff as the exclusive authority on the needs of dying individuals. As hospice agencies grow and the industry matures, it is inevitable that organizational rules and procedures will be put in place to standardize care. More is known about best practices as a result, and it is easier to train staff to provide care that is consistent with organizational standards. Standardized care, however, is inconsistent with the stated hospice philosophy and promise to meet patients and their families where they are. As the examples provided here indicate, such organizational efforts may directly affect patients' experiences, are lacking in compassion, can undermine patients' autonomy, and can negatively influence their quality of life.

\section{Results and Discussion}

The end of life is a complicated time for terminally ill people and their families. Our use of Mishler's ${ }^{23}$ concept of narratives of resistance helps to acknowledge issues of power and hierarchy in healthcare contexts, which are frequently ignored. Recognizing and then responding to these narratives can create space to integrate the experiences of those who are on the margins into the larger narrative of hospice. Since our participants are deceased and not able to tell their own stories, we attempt to bring their experiences into the fold. As the examples here illustrate, there are numerous ways in which people can enact resistance and assert themselves at the end of life that are both active and passive. The three themes presented here, denying the imminence of death, requesting curative treatments, and opposing organizational constraints, illustrate the types of resistance narratives we have observed in hospice. They are important forms of health communication about quality of life, autonomy, values, and goals at the end of life.

What constitutes quality of life is a unique reflection of an individual's values and preferences and these characteristics are essential for achieving a good death for hospice patients. These narratives of resistance challenge hospice providers to consider how to respond when patients and families do not fully embrace a standard hospice plan of care, and when patient and family preferences might be communicated in unconventional or subtle ways. Medical care is important, but these narratives highlight the importance of the four other dimensions of quality of life and how their expression may vary from patient to patient. ${ }^{22}$ These moments of resistance should serve as clinical communication triggers that prompt hospice staff members to enter into conversation with patients about their care needs rather than interpreting this resistance as noncompliance. The hospice agencies caring for the patients who enacted the resistance narratives we analyzed continued to provide good care for their patients the majority of the time. While the care described in the third theme is questionable, the hospice team members involved did engage in post-death debriefings in an effort to improve care in the future. Nevertheless, each patient or their surrogates either received push back from the hospice agencies, or felt as if they would be censured if they voiced their concerns. Rather than view these moments of resistance as failures on the part of hospice staff to anticipate patients' needs or meet quality of life goals, we want to frame them as clinical opportunities.

These narratives of resistance may speak to a related issue about the evolution of hospice and subsequent structural and institutional changes. Reimbursement structures, for example, have changed little since national law formalized the Medicare Hospice Benefit in the 1980s. ${ }^{44}$ No matter the amount or type of care, hospices receive a per diem rate of about $\$ 150$ USD. In 2016, a rules change modified reimbursements in the hopes of making long stays less profitable by decreasing the per diem rate after the first 60 days of enrollment. ${ }^{45}$ While these changes may encourage hospices to be more selective about who they enroll and when, they do not correspond to the changes in the type of diagnoses that bring patients to hospice, the unique types of care they need, or the internal processes, such as electronic documentation, which place more demands on team members' time. While hospice leaders may see the ways in which these changes influence the 
workforce, it is not clear if they are equally aware of the ways in which such institutional forces move care further away from the foundations of hospice, which were driven by maximizing an individual patient's quality of life.

There are others ways in which institutional practices in hospice, specifically communication practices, can work counter to the hospice philosophy. ${ }^{22}$ An emphasis on lists (e.g., medical eligibility for hospice) versus patients' stories during team meetings places a greater emphasis on biomedical care than on other dimensions of quality of life. ${ }^{22}$ As Whitney ${ }^{21}$ notes, the discourse in hospice and palliative care settings then begin to resemble the very biomedical systems hospices sought to resist rather than an organization that provides unique and holistic care. In turn, what constitutes a good death is narrowly defined and cannot realistically deliver on a promise to provide individualized care. ${ }^{21}$ If hospice staff members view their patients' resistance solely as barriers to the delivery of care rather than efforts to exercise autonomy and opportunities to fine-tune care plans, they will lose standing in the communities they hope to serve. Other organizations and individuals, such as end of life doulas, may succeed in fulfilling the needs of dying people and their families by engaging in explicit talk about the dying process and accommodating quality of life needs.

There are several points during the course of an illness when patients may feel uncertainty. Entering hospice is one of them, especially considering how little exposure many have to the dying process. Patients and their families may find the onslaught of new healthcare providers, new medical equipment, new medications - not to mention a new philosophy of care, changed goals for treatment, and more certainty about their prognosis - difficult and uncomfortable. It is at this time they may feel least able to say no or to voice their preferences and concerns. What these narratives of resistance reveal is that unless members of the healthcare team have created the space from the very beginning for patients and their loved ones to establish their own boundaries or change their minds, it is not likely to occur later when patients are weaker, family members are tired, and both are more reliant upon hospice personnel than before. These cases highlight opportunities for hospice providers to put the hospice philosophy of care into action by exploring the needs of their patients, whether they accept hospice but resist the imminence of death, continue to want curative treatments, question the organizational rules and procedures, or demonstrate their autonomy in other novel ways.

Hospice philosophy advocates hope, not for a cure but for a death free of spiritual and physical pain. For some dying patients, hope may come in the form of invasive interventions and tedious medication regimens generally regarded by hospice professionals as unnecessary and inappropriate at the end of life. These cases may encourage us to rethink our less is more at the end of life bias in the contexts of hospice and palliative care. Resistance should first give hospice practitioners pause and then call upon them to consider the ways in which certain interventions or practices (e.g., scheduling visits from staff) requested by patients and families may enhance quality of life and perceptions of autonomy and control.

The modern hospice movement was founded in part to oppose aggressive treatment at the end of life, yet as hospice agencies grow they become subject to new rules and procedures, and pressures to standardize care and maximize efficiency. As a result, they may eventually come to resemble the medical institutions they initially resisted. ${ }^{46}$ These institutional structures will also influence the content and form of communication. We are not advocating a return to a grassroots, volunteer model. But in order to maintain the essence of the hospice philosophy, organizational policy and practice should consider resistance as a way to minimize marginalization and open up possibilities for living fully until a patient dies. ${ }^{25}$ Despite an implicit promise in hospice that patients will receive unique individualized care, caseloads, documentation procedures, training, and reimbursement structures encourages staff to streamline care through standardization. We may feel uncomfortable highlighting power inequalities between hospice physicians, nurses, social workers, chaplains, home health aides, and their patients because they have been socialized to engage this healthcare context in the same way as any other. Patients and families are also socialized to engage health practitioners in particular ways that reinforce the notion that clinicians are the experts. Dying patients are dependent on the members of their team for care and treatment and have to find ways to ensure they will not be abandoned or decertified if their treatment preferences place them outside of standard hospice treatment plans.

\section{Conclusions}

These cases illustrate three ways in which patients exercise control and attempt to realize their own subjective visions of quality of life within the hospice system. These narratives of resistance highlighted patients who accepted hospice care but denied the closeness of death, the ways in which uncommon interventions promoted the quality of life of patients who were aware they would die soon, and the importance of remembering how organizational rules and institutional practices sometimes have human costs. These are not the usual kinds of stories told in the literature about patient-physician (and other healthcare professionals) communication at the end of life. The canonical narratives in hospice focus on peaceful, passive dying. An analysis of these cases demonstrates how quality of life is more varied than initially envisioned or practiced, while illustrating ways that more effective communication about patients' values can uncover the motivations driving patients' needs and desires. These experiences help bring marginalized experiences into the fold. 
Although patients bring the everyday realities of their social lives (Mishler's ${ }^{23}$ Voice of the Lifeworld) into the presentation of their medical problems, these concerns can be difficult to consider in discussions about plans of care at the end of life. Patients may appear stubborn or ungrateful if they resist pain medication or require a pacemaker, or may be ashamed if they prefer to watch television instead of composing their life history or seeking closure. We must remain mindful that patient is a constructed social category. ${ }^{23}$ Patients are only partially patients. They are people who once lived outside of the confines of medical care. Narratives of resistance remind us that there is always a person on the receiving end whose complexity and fullness may not be captured by usual characterizations and patterns of practice.

\section{References}

1. National Hospice and Palliative Care Organization. What hospice means: learn what hospice care really means to patients and their families. Alexandria, VA, USA: National Hospice and Palliative Care Organization; 2014. Available from: http://www.nhpco.org/press-room/press-releases/what-hospice-means

2. Clark D. Total pain', disciplinary power and the body in the work of Cicely Saunders, 1958-1967. Soc Sci Med 1999;49:727-36.

3. Byock IR, Merriman MP. Measuring quality of life for patients with terminal illness: the Missoula-VITAS $₫$ quality of life index. J Palliat Med 1998;12:231-44.

4. Centers for Medicare and Medicaid Services. Medicare care choices model. Baltimore, MD, SUA: Centers for Medicare and Medicaid Services; 2016. Available from: https://innovation.cms.gov/initiatives/Medicare-care-Choices/

5. Emmanuel, LL, Alpert, HR, Baldwin, DC, Emanuel, EJ. What terminally ill patients care about: toward a validated construct of patients' perspectives. J Palliat Med 2000;3:419-31.

6. Johansson CM, Axelsson B, Danielson E. Living with incurable cancer at the end of life-patients' perceptions on quality of life. Cancer Nurs 2006;29:391-9.

7. Singer PA, Martin DK, Kelner M. Quality end-of-life care: Patients' perspectives. JAMA 1999;281:163-8.

8. Steinhauser KE, Christakis NA, Clipp EC, et al. Preparing for the end of life: preferences of patients, families, physicians, and other care providers. J Pain Symptom Manage 2001;22:727-37.

9. Steinhauser KE, Christakis NA, Clipp EC, et al. Factors considered important at the end of life by patients, family, physicians, and other care providers. JAMA 2000;284:2476-82.

10. Teno JM, Casey VA, Welch LC, Edgman-Levitan S. Patientfocused, family-centered end-of-life medical care: views of the guidelines and bereaved family members. J Pain Symptom Manage 2001;22:738-51.

11. Gill TM, Feinstein AR. A critical appraisal of the quality of quality-of-life measurements. JAMA 1994; 272:619-26.

12. Schonwetter RS, Roscoe LA, Nwosu M, et al. Quality-oflife and symptom control in hospice cancer patients receiving chemotherapy. J Palliat Med 2006;9:638-45.

13. Bochner AP, Ellis C, Tillmann-Healy L. Relationships as stories. In: S. Duck (ed.) Handbook of personal relation- ships: theory, research, and interventions (2nd ed., pp. 307324). New York, NY: John Wiley; 1997.

14. Bruner J. Acts of meaning. Cambridge, MA, USA: Harvard University Press; 1990.

15. Temel JS, Greer JA, Muzikansky A, et al. Early palliative care for patients with metastatic non-small-cell lung cancer. New Engl J Med 2010;363:733-42.

16. Connor SR, Pyenson B, Fitch K, et al. Comparing hospice and nonhospice patient survival among patients who die within a three-year window. J Pain Symptom Manage 2007; $33: 238-46$.

17. Stanford University Palliative Medicine. Where do Americans die? Palo Alto, CA, USA: Stanford School of Medicine; 2017. Available from: https://palliative.stanford.edu/home-hospicehome-care-of-the-dying-patient/where-do-americans-die/

18. Aries P. Western attitudes toward death: from the Middle Ages to the present. Baltimore, MD, USA: Johns Hopkins University Press; 1974.

19. Kubler-Ross E. On death and dying. New York, NY: Macmillan; 1969.

20. Nussbaum JF, Giles H, Worthington A. Communication at the end of life. New York, NY, USA: Peter Lang Publishing; 2015.

21. Whitney A. Discourse on or about dying: palliative care. In: Nussbaum, J. F. Giles, H. Worthington, A. (Eds). Communication at the end of life. New York, NY: Peter Lang Publishing; 2015.

22. Tullis Owen JA. Communicating spirituality, dying and a "good death" at the end-of life: the role of hospice interdisciplinary team members. Graduate Theses and Dissertations. University of South Florida. Available from: http://scholarcommons.usf.edu/etd/56

23. Mishler EG. Patient stories, narratives of resistance and the ethics of humane care: a la recherche du temps perdu. Health (London) 2005;4:431-51.

24. Stone-Mediatore S. Reading across borders: storytelling and knowledges of resistance. New York, NY, USA: Palgrave Macmillan; 2003.

25. Dutta M. Communicating health: a culture-centered approach. Cambridge: Polity; 2008.

26. Dillon, PJ, Roscoe, LA. African Americans and hospice care: a narrative analysis. Narrat Inq Bioeth 2015;5:151-65.

27. Dillon, PJ, Roscoe, LA, Jenkins, JJ. African Americans and decisions about hospice care: implications for health message design. Howard Journal of Communications 2012;23:175-93.

28. Tullis, JA. Participant observation at the end-of-life: reflecting on tears. Health Commun 2013;28:206-8.

29. Tullis, JA. Personhood and communication at the end of life. J Med Pers 2012;10:103-13.

30. Morse JM. Confusing categories and themes. Qual Health Res 2008;18:727-28.

31. Christakis NA. Death foretold: prophecy and prognosis in medical care. Chicago, IL: University of Chicago Press; 2001.

32. Roscoe LA, Tullis JA, Reich RR, McCaffrey JC. Beyond good intentions and patient perceptions: competing definitions of effective communication in head and neck cancer care at the end of life. Health Commun 2013;28:183-92.

33. Quill, TE. Initiating end-of-life discussions with seriously ill patients: addressing the "elephant in the room." JAMA 2000;284:2502-7.

34. Ellis C. Beyond measure: The role of stories, conversations, 
and personal narratives in quality of life research. J Med Pers 2008;6:104-12.

35. Bochner AP. Vulnerable medicine. J Appl Commun Res 2009;37:159-66.

36. Teno JM, Plotzke M, Gozalo P, Mor V. A national study of live discharges from hospice. J Palliative Med 2014;17:1121-7.

37. Dillon PJ, Basu A. African Americans and hospice care: a culture-centered exploration of enrollment disparities. Health Commun 2016;11:1385-94.

38. Dillon PJ, Roscoe LA. African Americans and hospice care: a narrative analysis. Narrative Inquiry Bioethics 2015;5:151-65.

39. Zellner RA, Aulisio MP, Lewis WR. Should implantable cardioverter-defibrillators and permanent pacemakers in patients with terminal illness be deactivated? Circ Arrhythm Electrophysiol 2009;2:340-4.

40. Sulmasy DP. Within you/without you: biotechnology, ontology, and ethics. J Gen Intern Med 2008;23(Suppl.1):69-72.

41. Kay GN, Bittner GT. Deactivating implantable cardioverterdefibrillators and permanent pacemakers: an ethical distinction. Circ Arrhythm Electrophysiol 2009;2:336-39.
42. Kapa S, Mueller PS, Hayes DL, Asirvatham SJ. Perspectives on withdrawing pacemaker and implantable cardioverterdefibrillator therapies at the end of life: results of a survey of medical and legal professionals and patients. Mayo Clin Pro 2010;85:981-90.

43. Morganweck CJ. Ethical considerations for discontinuing pacemakers and automatic implantable cardiac defibrillators at the end-of-life. Curr Opin Anaesthesiol 201;26:171-5.

44. Medicare Program; FY 2017 Hospice Wage Index and Payment Rate Update and Hospice Centers for Medicaid and Medicare Services Department of Health and Human Services. 5 Aug 2016 Available from: http://federalregister. gov/a/2016-18221

45. Stevenson D, Huskamp H. Hospice payment reforms are a modest step forward, but more changes are needed. 2016. Available from: http://healthaffairs.org/blog/2016/01/04/hospice-payment-reforms-are-a-modest-step-forward-but-morechanges-are-needed/

46. Ahrne G. Agency and organization: towards an organizational theory of society. Thousand Oaks, CA: Sage; 1990. 